\title{
Effects of Gibberellic Acid Responsive Dwarfing Gene Rht9 on Plant Height and Agronomic Traits in Common Wheat
}

\author{
Tay Zar Linn ${ }^{1}$, Daoura Goudia Bachir ${ }^{1}$, Liang Chen ${ }^{1}$, Yin-Gang $\mathrm{Hu}^{1,2, ~ *}$ \\ ${ }^{1}$ State Key Laboratory of Crop Stress Biology for Arid Areas, College of Agronomy, Northwest A\&F University, Yangling, P. R. China \\ ${ }^{2}$ Institute of Water Saving Agriculture in Arid Regions of China, Yangling, P. R. China
}

\section{Email address:}

tayzarlinn308@gmail.com (T. Z. Linn), bachirdaoura@yahoo.fr (D. G. Bachir), chenliang9117@nwafu.edu.cn (Liang Chen), huyingang@nwsuaf.edu.cn (Yin-Gang Hu)

${ }^{*}$ Corresponding author

\section{To cite this article:}

Tay Zar Linn, Daoura Goudia Bachir, Liang Chen, Yin-Gang Hu. Effects of Gibberellic Acid Responsive Dwarfing Gene Rht9 on Plant Height and Agronomic Traits in Common Wheat American Journal of Agriculture and Forestry. Vol. 5, No. 4, 2017, pp. $102-111$. doi: 10.11648/j.ajaf.20170504.14

Received: May 11, 2017; Accepted: May 20, 2017; Published: July 7, 2017

\begin{abstract}
To explore the potential use of GA-responsive dwarfing gene Rht 9 in common wheat breeding program, its effects on plant height, seedling vigor, photosynthesis and yield traits were investigated and compared in field experiments using hexaploid $R h t 9$ dwarf lines derived from two crosses of Chinese winter wheat cultivars Xifeng 20 and Jinmai 47 with the Rht 9 tetraploid donor Granaoto. Xifeng20-Rht 9 dwarf lines reduced plant height on average by $25.38 \%$, while on average by $9.39 \%$ in Jinmai47-Rht9/Rht8 dwarf lines. Compared with taller parents, coleoptile length was reduced by $19.80 \%$ in Xifeng20-Rht 9 dwarf lines, while it was increased by $14.22 \%$ in Jinmai $47-R h t 9 / R h t 8$ dwarf lines. There were no adverse effects of $R h t 9$ on root characters and flag leaf characters, though slightly increased relative leaf chlorophyll content (SPAD) observed. Grain numbers per spike was increased on average by $19.63 \%$, and biomass per plant was slightly decreased on average by $3.37 \%$ in Xifeng 20-Rht9 dwarf lines, while, grain number per spike was decreased on average by $11.49 \%$, and biomass per plant was increased on average by $8.57 \%$ in Jinmai $47-R h t 9 / R h t 8$ dwarf lines. Compared with taller parents, $R h t 9$ increased fertile tillers on average by $11.25 \%$ and $11.19 \%$, grain yield on average by $10.11 \%$ and $14.10 \%$, harvest index on average by $12.67 \%$ and $6.85 \%$, while decreased spike length on average by $4.80 \%$ and $16.23 \%$, slightly decreased 1000 kernels weight by $4.43 \%$ and $4.61 \%$, in the Rht 9 dwarf lines of Xifeng 20 and Jinmai 47, respectively. The results of current study could be useful for proper use of dwarfing gene $R h t 9$ to improve lodging resistance, grain yield potential in wheat breeding programs for water limited area.
\end{abstract}

Keywords: Dwarfing Genes, Rht8, Rht9, Plant Height, Seedling Vigor, Yield, Wheat

\section{Introduction}

Wheat is grown mostly in arid and semiarid regions, taking about one fifth of all crop acreage worldwide, and is the staple food for $40 \%$ of the world's population [1]. Due to the increasing global population and limited arable land, wheat production and yield improvement become more and more important. The introduction of semi-dwarfing genes into rice (Oryza sativa) and wheat (Triticum aestivum) contributes prominent yield increases during the Green Revolution [2]. High yields were associated with improved lodging resistance and the ability to tolerate higher rates of inorganic nitrogen-based fertilizers [3]. The use of dwarfing genes to reduce plant height, increase harvest index, improve lodging resistance and increase grain yield has been one of the major strategies in developing modern bread wheat cultivars.

Most of the dwarf and semi-dwarf wheat lines in Europe have inherited dwarfing genes from the Japanese wheat landrace Akakomugi, which is the donor of the dwarf gene $R h t 8$ and the photoperiod-insensitive gene $P p d-D 1$, both genes are closely linked and located on chromosome 2D [3]. Donor of dwarfing genes $R h t-B 1$ and $R h t-D 1$ from Japanese origin variety Norin 10 was first introduced to United State, then to CIMMYT, where new semi-dwarf wheat varieties were developed by Norman Bourlag (1968) and then 
followed by other wheat breeding programs worldwide [3, 4]. Dwarfing genes are classified according to their sensitivity to externally applied gibberellins (GAs) [5]. Rht-Blb and Rht$D 1 b$ are GA-insensitive (GAI) genes, conferring the dwarf phenotype, and the wild type alleles are $R h t-B 1 a$ and $R h t$ $D 1 a$, while $R h t 8$ is a GA-responsive gene. Rht-Blb and Rht$D 1 b$ are probably present in around $90 \%$ of the world's semidwarf wheat crops and responsible for the worldwide green revolution in wheat [6]. Rht-B1b and $R h t-D 1 b$, located on homoeologous chromosome arms of 4BS and 4DS, had pleiotropic effects on plant growth, causing reductions in coleoptile length and seedling leaf area [7]. The effect of the $R h t-B 1$ and Rht-D1 on height reduction is commonly reported at around $20-25 \%$ of the wild-type allele but it varies with different genetic background and environment [810]. Apart from reducing the plant height of wheat, dwarfing genes $R h t-B 1 b$, Rht-D1b also decrease the coleoptiles length, the seedling rate and population density $[11,12]$. Therefore the use of GAI dwarfing genes is not recommended in dry land environments. The development of wheat cultivars with greater seedling vigor and the capacity to emerge from deep sowing becomes very interesting for wheat breeders $[13,14]$.

Replacement of the Rht-B1b and Rht-D1b GAI-dwarfing alleles with alternate gibberellic acid-responsive (GAR) dwarfing genes shows its potential in reducing plant height without compromising seedling vigor [14-17]. Several studies have been conducted to demonstrate the potential of Rht8 in the development of semi-dwarf, long coleoptiles wheat targeted at sowing depths exceeding $100 \mathrm{~mm}[11,14]$. $R h t 8$ has a smaller effect on height reduction (8-12\%) than the GAI ones Rht-B1b, Rht-Blc and Rht-D1b [13, 17, 18]. Rht8 allele has been shown to reduce plant height and increase carbon-partitioning in grains to increase the grain number and yield [13]. In addition to $R h t 8$, there are some other major GAR dwarfing genes (e.g. Rht4, Rht5, Rht9, Rht12, Rht13, Rht14 and Rht18) that reduce plant height by as much as $50 \%$ when compared with tall-parental or nearisogenic controls [17-20]. However, they are seemingly neutral in their effects on coleoptile length and seedling vigor $[17,21,22]$. Coleoptile length for progenies derived from $R h t 8$ and $R h t 9$ donors is generally reduced (7 to $13 \%$ ) but is still $47 \%$ longer than that of Rht-B1b and Rht-Dlb controls on average [16]. However, genetic and agronomic studies have demonstrated the potential for $R h t 8$ and $R h t 9$ in the development of high-yielding, reduced height wheat with long coleoptiles $[13,14]$.

Marker assisted selection (MAS) is efficient in selecting the traits contributed by the specific genes in their segregating populations. PCR-based markers have been developed for discriminating between mutant (dwarf) $R h t B 1 b$ and $R h t D 1 b$ and their wild type alleles [23], while Rht8 was linked to markers WMC503 and WMS 261 on chromosome 2DS and Rht9 was linked to marker BARC 151 on chromosome $5 \mathrm{AL}$ in the Chuan Mai $18($ Rht8) $\times$ Mara
(Rht8/Rht9) population, and Rht9 semi-dwarf lines were on average 5 to $7 \mathrm{~cm}$ shorter than $R h t 8$ lines, with a small but significant height reduction effect [18].

In this study, two Chinese winter wheat cultivars Xifeng 20 (without known dwarfing genes) and Jinmai47 (with $R h t 8$ ) were crossed with $R h t 9$ donor Granato (AABB), and the SSR markers BARC 151 for $R h t 9$ and WMC503 for $R h t 8$ were used to identify the genotypes of each hexiploid dwarfing lines to evaluate the effects of dwarfing gene $R h t 9$ and its combination with Rht8 on plant height, coleoptile length, root length, photosynthesis-related traits and yield traits of common wheat in two genetic backgrounds, to better understand the potential use of Rht9 in common wheat improvement.

\section{Materials and Methods}

\subsection{Plant Materials}

The Rht 9 dwarfing lines used in this study were initially derived from two crosses between two Chinese winter wheat cultivars, Xifeng 20 and Jinmai 47 with Granato (AABB), the Rht9 donor with tetraploid wheat background. Jinmai47, carrying $R h t 8$, and Xifeng 20, with no known dwarfing genes, are winter wheat cultivars widely grown in the dryland areas of northern China. $\mathrm{F}_{1}$ plants from the two crosses were self-pollinated to produce $\mathrm{F}_{2}$ progeny by covering the spikes with paper bags before flowering. Hexaploid individuals of each $F_{2}$ populations were selected based on the presence of targeted gene with the aid of the linked markers and plant height. The hexaploid $\mathrm{F}_{2}$ individuals carrying $R h t 9$ allele were used to develop the Rht9 dwarf lines of Xifeng 20 and Jinmai 47 for successive generations of self-pollinating. $\mathrm{BC}_{1} \mathrm{~F}_{1}$ population was developed by crossing $\mathrm{F}_{1}$ plants of Jinmai $47 /$ Granato with Jinmai 47 , and then the hexaploid $\mathrm{BC}_{1} \mathrm{~F}_{2}$ individuals were selected to develop $\mathrm{BC}_{1}$ dwarfing lines. The numbers of lines from the two crosses of Xifeng 20/Granato, Jinmai47/Granato used in this study are shown in Table 1. As Rht8 located in chromosome 2DS of Jinmai47 [18], so all the Rht 9 dwarfing lines of Jinmai47 carried Rht8.

\subsection{Filed Experiments}

Field experiments were conducted at the experimental farm of Northwest A\&F University (Shaanxi, P. R. China). Eleven Rht9 dwarfing lines of Xifeng 20 and 13 Rht 9 dwarfing lines of Jinmai 47, which were identified with $R h t 9$, were sown next to their corresponding parental varieties during the growing seasons of 2014-2015 and 2015-2016. Complete randomized block designs were adopted with two replications. Each line was sown by hand in 3 rows of $2 \mathrm{~m}$ long with an interval of $25 \mathrm{~cm}$ between rows and $6.7 \mathrm{~cm}$ within plants. No irrigation was provided, so wheat growth relied on the moisture in the soil at sowing and the rainfall in the season. 
Table 1. Number of entries of the hexaploid Rht9 dwarf lines from two crosses between Chinese winter-wheat cultivars, Xifeng20 and Jinmai47 with Granato.

\begin{tabular}{lllll}
\hline Crosses & Generations (2014-15) & Generations (2015-16) & Number of Lines & Genotypes \\
\hline Xifeng20 $\times$ Granato & $\mathrm{F}_{6}$ & $\mathrm{~F}_{7}$ & 11 & 11 \\
$R h t 9$ dwarf lines of Xifeng20 & $\mathrm{F}_{6}$ & $\mathrm{~F}_{7}$ & 4 & $R h t 9$ \\
$($ Jinmai47 $\times$ Granato) & $\mathrm{F}_{5}$ & $\mathrm{~F}_{6}$ & 9 & \\
$($ Jinmai47 $\times$ Granato) $\times$ Jinmai47 & $\mathrm{BC}_{1} \mathrm{~F}_{4}$ & $\mathrm{BC}_{1} \mathrm{~F}_{5}$ & 13 & $R h t 9+R h t 8$ \\
$R h t 9$ dwarf lines of Jinmai47 & $\mathrm{F}_{5} \& \mathrm{BC}_{1} \mathrm{~F}_{4}$ & $\mathrm{~F}_{6} \& \mathrm{BC}_{1} \mathrm{~F}_{5}$ & \\
\hline
\end{tabular}

\subsection{Genotyping Rht9 with Linked SSR Marker}

Genomic DNA was extracted from the mixed fresh young leaves of 5 individuals for each line using CTAB method [24]. Polymerase chain reaction (PCR) were performed with the SSR marker BARC 151 to identify the presence of Rht9, while WMC 503 for $R h t-8$, as previously reported $[18,25]$. The PCR products were separated on $8 \%$ denatured polyacrylamide gels and were visualized by silver staining following the procedure described [26].

\subsection{Traits Evaluation}

\subsubsection{Plant Height and Internode Characters}

Ten plants were randomly selected at maturity (Z80) [27] from each line and their tall parents. Plant height and internode length were measured individually to calculate the means of plant height and internode length. The length of the internode below the spike was defined as peduncle length (PL), length of the second internode from top was defined as (I2L), followed by the length of the third (I3L), forth (I4L), and fifth (I5L) internode, respectively. Each internode length was measured from the mid-point of their subtending nodes.

\subsubsection{Coleoptile Length and Seedling Root Characters}

Good quality seeds of similar seeds and free of any visible damage from $\mathrm{F}_{7}$ lines of Xifeng20, $\mathrm{F}_{6} \& \mathrm{BC}_{1} \mathrm{~F}_{5}$ lines of Jinmai47 and parents were used to investigate coleoptile length (CL) and seedling root characteristics with two replications. Briefly, ten uniform-sized seeds without physical damage were placed on the fitter paper in the Petridishes. The Petri-dishes were then placed in the dark room at $20^{\circ} \mathrm{C}$ for 10 days. Coleoptile length (CL) was recorded to the nearest millimeter measuring from the base of the seed to the coleoptile tip.

An additional ten uniform-sized seeds were pre-sterilized (soaked in 75\% ethanol for 30 seconds and rinsed with sterile de-ionized water 5-6 times) and placed in a row $2 \mathrm{~cm}$ from the edge of a $20 \mathrm{~cm} \times 20 \mathrm{~cm}$ germination paper. The germination paper were rolled and placed vertically, with seeds at the top, into a container with $1 \mathrm{~cm}$ of water at the bottom. The container was then placed into an incubator at $20^{\circ} \mathrm{C}$ until the accumulated temperature reached $200^{\circ} \mathrm{C} \mathrm{d}$. Root number per plant (RN) were determined, and root length (RL) were measured with a ruler. Total root length (TRL), average root diameter (ARD), root surface area (RSA) and root volume (RV) were recorded using a flatbed scanner (Epson Expression 4990) and analyzed with WinRHIZO Pro (Regent Instruments, QC, Canada) [28].

\subsubsection{Assessment of Photosynthesis-Related Traits}

Flag leaf length (FLL), flag leaf width (FLW), the relative content of leaf chlorophyll (SPAD), the photosynthesis rate (A), stomatal conductance (gs), internal $\mathrm{CO}_{2}$ concentration $\left(\mathrm{C}_{\mathrm{i}}\right)$, transpiration rate $(\mathrm{E})$ of the flag leaf were recorded from plots of $\mathrm{F}_{7}$ lines of Xifeng20, $\mathrm{F}_{6} \& \mathrm{BC}_{1} \mathrm{~F}_{5}$ lines of Jinmai47 and parents in 2015-2016 growth season.

Flag leaf length (FLL), flag leaf width (FLW) and the relative content of leaf chlorophyll (SPAD) were recorded at early grain-filling stage (Z70) [27]. Flag leaf width (FLW) was recorded by measuring at the middle of the leaf. SPAD value was determined as the average at the base, middle and top of the flag leaf with a SPAD-502 chlorophyll meter (Minolta Co., Ltd, Japan) [29].

At anthesis (Z65) and early grain-filling (Z73) stages, the photosynthetic rate (A), stomatal conductance (gs), transpiration rate $(\mathrm{E})$ of the flag leaf were measured with a portable photosynthesis system (Li-6400, USA). Conditions in the leaf chamber were as reference $\mathrm{CO}_{2}$ concentration at $400 \mu \mathrm{mol} \mathrm{mol}{ }^{-1}$, Photosynthetic Photon Flux Density (PPFD) at $1800 \mu \mathrm{mol} \mathrm{m} \mathrm{m}^{-1}$, relative humidity of $50-70 \%$ and block temperature of $20^{\circ} \mathrm{C}$. Photosynthetic traits were measured for five plants of each line at 9:00-11:00 am in sunny and windless weather.

\subsubsection{Assessment of Agronomic Traits}

From plots of $\mathrm{F}_{6}$ and $\mathrm{F}_{7}$ lines of Xifeng20, $\mathrm{F}_{5} \& \mathrm{BC}_{1} \mathrm{~F}_{4}$ and $\mathrm{F}_{6} \& \mathrm{BC}_{1} \mathrm{~F}_{5}$ lines of Jinmai47 and their corresponding parents, ten plants were randomly selected and measured individually to estimate the means of the spike length (SL), spikelet number per spike (SNPS), grain number per spike (GNPS) and the number of fertile tillers per plant (FT), biomass per plant (BM), grain yield per plant (GY), harvest index (HI) in the two growing seasons. Distance from spike to flag leaf ligule (DSL), internodes length and 1000-kernel weight (TKW) were recorded from plots of $F_{7}$ lines of Xifeng20, $\mathrm{F}_{6} \& \mathrm{BC}_{1} \quad \mathrm{~F}_{5}$ lines of Jinmai47 and parents in 2015-2016 growth season.

Ten plants were randomly selected from each line and hand harvested at maturity. The main shoot from each plant was used to measure the spike length (SL), spikelet number per spike (SNPS), grain number per spike (GNPS) and the number of fertile tillers per plant (FT). Biomass and grain yield were recorded for the 10 plants and then calculated as the biomass per plant (BM) and grain yield per plant (GY). Harvest index (HI) was calculated as a ratio of grain weight to aboveground biomass. 1000-kernel weight (TKW) was 
recorded.

\subsection{Statistical Analysis}

The mean values of all traits for each line were determined and the effects of dwarfing gene $R h t 9$ were estimated following the formula, effect $=\left(\mathrm{X}_{\text {Dwarf }}-\right.$ $\left.\mathrm{X}_{\text {Tal1 }}\right) / \mathrm{X}_{\text {Tall }} \times 100 \%$, where $\mathrm{X}_{\text {Dwarf }}$ is the mean value of the Rht 9 lines and $\mathrm{X}_{\text {Tall }}$ is the mean value of the taller parent. Statistical analysis was carried out by t- test using SAS procedure to compare the significance of difference between the mean of dwarf lines and their corresponding tall parents (SAS Institute Inc, Cary, NC, USA). Phenotypic correlation coefficients between plant heights with other agronomic traits were worked out with the help of SPSS 16.0 for Windows. Significance of difference was designated by $p<0.05(*)$ and $p<0.01(* *)$, respectively.

\section{Results}

\subsection{Genotyping of Rht9 with SSR Marker}

$R h t 9$ dwarf lines of Xifeng20 and Jinmai47 were identified by the PCR products using the linked SSR marker BARC151 for $R h t 9$, while the presence of Rht8 in the dwarfing lines of Jinmai47 was also confirmed using WMC503, which suggested that the Rht9 dwarfing lines of Jinmai47 was under the Rht 8 background (Figure 1). Genotyping with SSR marker BARC151 showed a 220bp product in Granato and 230bp product in Xifeng20 and Jinmai 47, and confirmed the presence of Rht9 the dwarf lines of Xifeng20 and Jinmai 47. Genotyping with SSR marker WMC503 showed a 240bp product in Jinmai47 (Rht8) and a 270bp product in Granato ( $r h t 8$ ), and confirmed the presence of $R h t 8$ in the dwarf lines of Jinmai47 as well. Thus, the dwarfing lines of Jinmai47/Granato were identified as double dwarf (Rht9/Rht8).
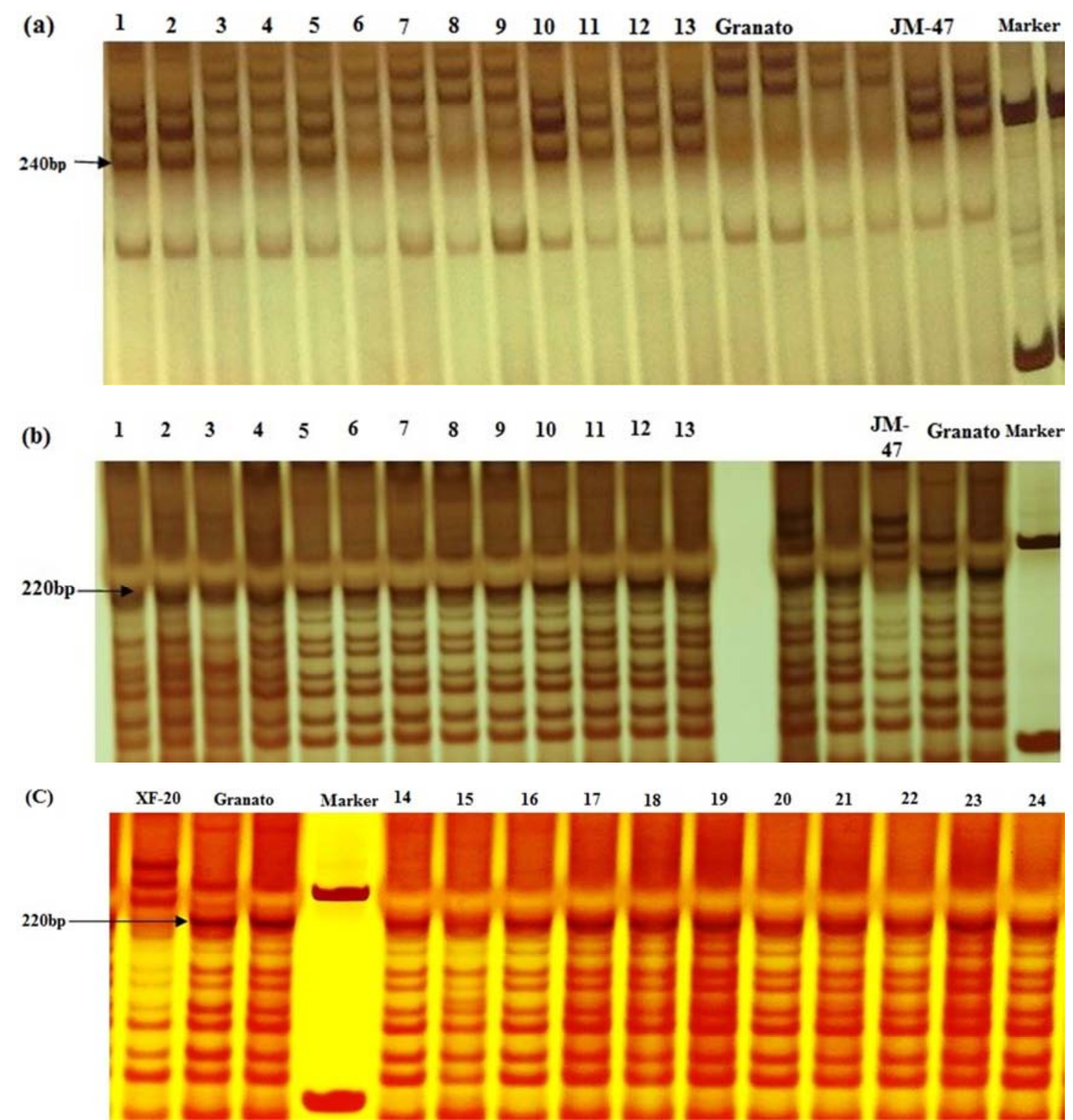

JM-47; Jinmai47, XF-20; Xifeng20, 1-13; dwarf individuals of Jinmai47 (Rht9/Rht8), 14-24; dwarf individuals of Xifeng20 (Rht9).

Figure 1. Detection of dwarfing genes Rht8 and Rht9 with their linked SSR marker WMC503 and BARC151 (a) Detection of Rht8 with WMC503 in the dwarf lines of Jinmai47; (b) Detection of Rht9 with BARC151 in the dwarflines of Jinmai47; (c) Detection of Rht9 with BARC151 in the dwarf lines of Xifeng20. 
Table 2. Plant height and main agronomic traits of $F_{6}$ Rht 9 dwarfing lines of Xifeng 20 and $F_{5} \& B C_{1} F_{4}$ Rht 9 dwarf lines of Jinmai47 with their corresponding tall parents.

\begin{tabular}{lllllll}
\hline \multirow{2}{*}{ Traits } & Xifeng20/Granato & & \multicolumn{3}{l}{ Jinmai47/Granato } \\
\cline { 2 - 7 } & Dwarf & Xifeng20 & Difference & Dwarf & Jinmai47 & Difference \\
\hline PH $(\mathrm{cm})$ & $91.31 \pm 2.83$ & $120.89 \pm 5.54$ & $-29.58(-24.47 \%)^{* *}$ & $96.02 \pm 4.81$ & $102.58 \pm 0.38$ & $-6.56(-6.40 \%)^{*}$ \\
SL $(\mathrm{cm})$ & $10.27 \pm 0.23$ & $11.17 \pm 0.07$ & $-0.90(-8.06 \%)^{* *}$ & $9.22 \pm 0.67$ & $11.20 \pm 0.13$ & $-1.98(-17.68 \%)^{* *}$ \\
SNPS & $21.21 \pm 0.61$ & $20.16 \pm 0.70$ & $1.05(5.21 \%) \mathrm{ns}$ & $18.26 \pm 0.98$ & $18.33 \pm 0.76$ & $-0.07(-0.38 \%) \mathrm{ns}$ \\
FT & $13.35 \pm 1.41$ & $12.25 \pm 0.25$ & $1.10(8.98 \%)^{*}$ & $14.67 \pm 1.31$ & $13.39 \pm 1.08$ & $1.28(9.56 \%)^{*}$ \\
GNPS & $67.02 \pm 2.92$ & $54.16 \pm 2.02$ & $12.86(23.74 \%)^{* *}$ & $53.24 \pm 6.15$ & $58.83 \pm 8.51$ & $-5.59(-9.50 \%)^{*}$ \\
BM (gm) & $47.36 \pm 7.51$ & $47.61 \pm 0.00$ & $-0.25(-0.53 \%) \mathrm{ns}$ & $52.32 \pm 6.00$ & $46.70 \pm 0.00$ & $5.62(12.04 \%)^{*}$ \\
GY (gm) & $21.99 \pm 3.05$ & $19.67 \pm 0.00$ & $2.32(11.79 \%)^{*}$ & $23.61 \pm 2.09$ & $19.80 \pm 0.00$ & $3.81(19.19 \%)^{*}$ \\
HI \% & $0.46 \pm 0.25$ & $0.41 \pm 0.00$ & $0.05(12.00 \%)^{* *}$ & $0.46 \pm 0.03$ & $0.42 \pm 0.00$ & $0.04(9.52 \%) \mathrm{ns}$ \\
\hline
\end{tabular}

PH, plant height $(\mathrm{cm})$, SL, The spike length $(\mathrm{cm})$; SNPS, Spikelet number per spike; FT, The number of fertile tillers per plant; GNPS, Grain number per spike; BM, The biomass per plant (gram); GY, Grain yield per plant (gram); HI, Harvest Index \%. Data are means \pm SD (standard deviation) of each genotype. Difference was calculated as the value of dwarf lines minus that of the tall parent; the percentage difference was estimated as the difference to tall parent and is shown in parentheses. ns indicates that differences are not significant. * and ** indicates differences between the dwarfing lines and tall parent significant at $\mathrm{p}<0.05$, and $\mathrm{p}<0.01$, respectively.

Table 3. Plant height and main agronomic traits of $F_{7}$ Rht 9 dwarfing lines of Xifeng 20 and $F_{6} \& B C_{1} F_{5}$ Rht 9 dwarf lines of Jinmai47 with their corresponding tall parents.

\begin{tabular}{|c|c|c|c|c|c|c|}
\hline \multirow{2}{*}{ Traits } & \multicolumn{3}{|c|}{ Xifeng20/Granato } & \multicolumn{3}{|c|}{ Jinmai47/Granato } \\
\hline & Dwarf & Xifeng20 & Difference & Dwarf & Xifeng20 & Difference \\
\hline $\mathrm{PH}(\mathrm{cm})$ & $76.35 \pm 3.02$ & $103.58 \pm 3.57$ & $-27.23(-26.29 \%)^{* *}$ & $82.50 \pm 6.33$ & $94.16 \pm 1.33$ & $-11.66(-12.38 \%)^{* *}$ \\
\hline $\mathrm{SL}(\mathrm{cm})$ & $8.95 \pm 0.34$ & $9.11 \pm 0.58$ & $-0.16(-1.54 \%) \mathrm{ns}$ & $7.50 \pm 0.85$ & $8.80 \pm 0.33$ & $-1.30(-14.77 \%)^{*}$ \\
\hline SNPS & $18.72 \pm 0.41$ & $17.97 \pm 0.91$ & $0.75(4.17 \%) \mathrm{ns}$ & $16.50 \pm 1.25$ & $17.78 \pm 0.98$ & $-1.28(-7.20 \%) \mathrm{ns}$ \\
\hline FT & $8.98 \pm 0.60$ & $7.91 \pm 0.36$ & $1.07(13.53 \%)^{*}$ & $7.83 \pm 0.59$ & $6.94 \pm 0.47$ & $0.89(12.82 \%)^{*}$ \\
\hline GNPS & $54.80 \pm 2.77$ & $47.44 \pm 5.64$ & $7.36(15.51 \%)^{*}$ & $45.95 \pm 5.16$ & $53.11 \pm 3.42$ & $-7.16(-13.48 \%)^{*}$ \\
\hline $\mathrm{BM}(\mathrm{gm})$ & $31.11 \pm 1.62$ & $33.18 \pm 7.31$ & $-2.07(-6.21 \%) \mathrm{ns}$ & $31.73 \pm 3.10$ & $30.19 \pm 1.67$ & $1.54(5.10 \%) \mathrm{ns}$ \\
\hline $\mathrm{HI} \%$ & $0.51 \pm 0.02$ & $0.45 \pm 0.01$ & $0.06(13.33 \%)^{* *}$ & $0.50 \pm 0.02$ & $0.48 \pm 0.02$ & $0.02(4.17 \%) \mathrm{ns}$ \\
\hline TKW (gm) & $41.55 \pm 1.02$ & $43.47 \pm 0.98$ & $-1.92(-4.43 \%) \mathrm{ns}$ & $47.81 \pm 4.88$ & $50.12 \pm 0.45$ & $-2.31(-4.61 \%) n s$ \\
\hline
\end{tabular}

PH, plant height $(\mathrm{cm})$, SL, The spike length (cm); SNPS, Spikelet number per spike; FT, The number of fertile tillers per plant; GNPS, Grain number per spike; BM, The biomass per plant (gram); GY, Grain yield per plant (gram); HI, Harvest Index \%; TKW, 1000 kernel weight (gram). Data are means \pm SD (standard deviation) of each genotype. Difference was calculated as the value of dwarf lines minus that of the tall parent; the percentage difference was estimated as the difference to tall parent and is shown in parentheses. ns indicates that differences are not significant.

$*$ and $* *$ indicates differences between the dwarfing lines and tall parent significant at $\mathrm{p}<0.05$, and $\mathrm{p}<0.01$, respectively.

\subsection{The Effects of Rht9 on Plant Height and Internode Lengths}

Compared with their tall parental varieties, plant height ( $\mathrm{PH})$ was significantly reduced in the $R h t 9$ dwarfing lines of the two populations (Table 2, Table 3). PH was significantly reduced by $24.47 \%$ and $26.29 \%$ in the $\mathrm{F}_{6}$ and $\mathrm{F}_{7}$ Rht 9 dwarf lines of Xifeng 20, respectively (Table 2) and by $6.40 \%$ and $12.38 \%$ in the $\mathrm{F}_{5} \& \mathrm{BC}_{1} \mathrm{~F}_{4}$ and $\mathrm{F}_{6} \& \mathrm{BC}_{1} \mathrm{~F}_{5}$ Rht 9 dwarf lines of Jinmai47, respectively compared with their taller parents (Table 3). The peduncle length (PL), the lengths of the second (I2L), third (I3L), fourth (I4L) and fifth (I5L) internode from the top were decreased significantly by $23.40 \%, 30.60 \%, 31.20 \%, 36.50 \%$ and $25.10 \%$, respectively in the $\mathrm{F}_{7}$ Rht 9 dwarf lines of Xifeng 20 than Xifeng 20 (Table 4). The lengths of the second (I2L), and third (I3L) internode from the top were significantly decreased by $15.80 \%$ and $13.13 \%$ in $\mathrm{F}_{6} \& \mathrm{BC}_{1} \mathrm{~F}_{5}$ Rht 9 dwarf lines of Jinmai 47 than Jinmai 47 , and there were no significant differences on the peduncle length (PL), and other internodes (Table 4). The distance from spike to flag-leaf ligule (DSL) was significantly reduced by $34.10 \%$ in $\mathrm{F}_{7}$ Rht 9 dwarf lines of
Xifeng 20, while it was significantly increased by $50.60 \%$ in $\mathrm{F}_{6} \& \mathrm{BC}_{1} \mathrm{~F}_{5}$ Rht 9 dwarf lines of Jinmai47 (Table 4). The effects of $R h t 9$ on the lengths of different internodes varied in the two genetic backgrounds, which were stronger in the background of Xifeng 20, a variety with no known dwarfing genes, than that in the background of Jinmai47, which carried the GAR dwarfing gene Rht8. This indicated that there may have some interactions between $R h t 9$ and $R h t 8$.

\subsection{The Effects of Rht9 on Agronomic Traits}

Compared with Xifeng 20, the number of fertile tillers per plant (FT) was significantly increased by $8.98 \%$ and $13.53 \%$ in $\mathrm{F}_{6}$ and $\mathrm{F}_{7}$ Rht 9 dwarf lines of Xifeng20, respectively and grain number per spike (GNPS) was also significantly increased by $23.74 \%$ and $15.51 \%$ in $\mathrm{F}_{6}$ and $\mathrm{F}_{7}$ Rht 9 dwarf lines of Xifen 20, respectively (Table 2 and Table 3). The biomass per plant (BM) was slightly reduced, grain yield per plant (GY) was slightly increased in the $F_{6}$ and $F_{7}$ lines of Xifeng 20, while harvest index (HI) were significantly increased by $12.00 \%$ and $13.33 \%$ in $\mathrm{F}_{6}$ and $\mathrm{F}_{7}$ Rht 9 dwarf lines of Xifeng 20, respectively (Table 2 and Table 3 ). The $F_{7}$ $R h t 9$ dwarf lines of Xifeng 20 showed $4.43 \%$ decrease in 
1000 kernels weight (TKW) (Table 3).

Compared with Jinmai47, spike length (SL) was significantly decreased by $17.68 \%$ and $14.77 \%$ and grain number per spike (GNPS) was significantly decreased by $9.50 \%$ and $13.48 \%$, while the number of fertile tillers per plant (FT) was significantly increased by $9.56 \%$ and $12.82 \%$ in $\mathrm{F}_{5} \& \mathrm{BC}_{1} \mathrm{~F}_{4}$ and $\mathrm{F}_{6} \& \mathrm{BC}_{1} \mathrm{~F}_{5}$ Rht 9 dwarf lines of Jinmai47, respectively (Table 2 and Table 3 ). Biomasses per plant $(\mathrm{BM})$, grain yield per plant (GY) were significantly increased by $12.04 \%$ and $19.19 \%$ and harvest index was slightly increased in the $\mathrm{F}_{5} \& \mathrm{BC}_{1} \mathrm{~F}_{4}$ Rht 9 dwarf lines of Jinmai 47 (Table 2). $\mathrm{F}_{6} \& \mathrm{BC}_{1} \mathrm{~F}_{5}$ Rht9 dwarf lines of Jinmai 47 showed $5.10 \%$ increase in biomass per plant (BM), $9.01 \%$ increase in grain yield per plant (GY) and $4.17 \%$ increase of harvest index (HI) but their differences between the dwarf lines and tall parent were not significant (Table 3). 1000 kernels weight (TKW) was slightly decreased by $4.61 \%$ in $R h t 9$ dwarf lines of Jinmai 47 (Table 3). These results indicated that the effects of $R h t 9$ on grain number per spike (GNPS) and biomass per plant $(\mathrm{BM})$ varied with different genetic backgrounds.

Table 4. Plant height related traits of $F_{7}$ Rht9 dwarfing lines of Xifeng20 and $F_{6} \& B C_{1} F_{5}$ Rht 9 dwarf lines of Jinmai47 with their corresponding tall parents.

\begin{tabular}{|c|c|c|c|c|c|c|}
\hline \multirow{2}{*}{ Traits } & \multicolumn{3}{|c|}{ Xifeng20/Granato } & \multicolumn{3}{|c|}{ Jinmai47/Granato } \\
\hline & Dwarf & Xifeng20 & Difference & Dwarf & Xifeng20 & Difference \\
\hline $\mathrm{PH}(\mathrm{cm})$ & $76.35 \pm 3.02$ & $103.58 \pm 3.57$ & $-27.23(-26.29 \%)^{* *}$ & $82.50 \pm 6.33$ & $94.16 \pm 1.33$ & $-11.66(-12.38 \%)^{* *}$ \\
\hline PL (cm) & $24.46 \pm 1.43$ & $31.92 \pm 4.57$ & $-7.46(-23.40 \%)^{* *}$ & $22.44 \pm 1.57$ & $23.88 \pm 1.31$ & $-1.44(-6.00 \%) \mathrm{ns}$ \\
\hline $\mathrm{I} 2 \mathrm{~L}(\mathrm{~cm})$ & $17.53 \pm 0.60$ & $25.26 \pm 1.92$ & $-7.73(-30.60 \%) * *$ & $20.94 \pm 1.99$ & $24.88 \pm 0.29$ & $-3.94(-15.80 \%)^{* *}$ \\
\hline $\mathrm{I} 3 \mathrm{~L}(\mathrm{~cm})$ & $12.27 \pm 0.67$ & $17.84 \pm 1.18$ & $-5.57(-31.20 \%)^{* *}$ & $15.63 \pm 2.29$ & $18 \pm 1.15$ & $-2.37(-13.13 \%)^{*}$ \\
\hline $\mathrm{I} 4 \mathrm{~L}(\mathrm{~cm})$ & $7.92 \pm 0.62$ & $12.48 \pm 1.54$ & $-4.56(-36.50 \%)^{* *}$ & $10.28 \pm 2.18$ & $11.55 \pm 0.75$ & $-1.27(-10.90 \%) \mathrm{ns}$ \\
\hline $\mathrm{I} 5 \mathrm{~L}(\mathrm{~cm})$ & $5.50 \pm 0.68$ & $7.34 \pm 1.96$ & $-1.84(-25.10 \%)^{*}$ & $4.81 \pm 0.96$ & $4.75 \pm 2.06$ & $0.06(1.30 \%) \mathrm{ns}$ \\
\hline
\end{tabular}

PH, plant height $(\mathrm{cm})$; PL, peduncle length $(\mathrm{cm})$; I2L, I3L, I4L, I5L, length of the second, third, fourth and fifth internode from top (cm), respectively; DSL, distance from base of the spike to the flag ligule $(\mathrm{cm})$;

Data are mean \pm SD (standard deviation) of each genotype. Difference was calculated as the value of dwarf lines minus that of the tall parent; the percentage difference was estimated as the difference to tall parent and is shown in parentheses. ns indicates that differences are not significant. $*$ and $* *$ indicates differences between the dwarfing lines and tall parent significant at $\mathrm{p}<0.05$, and $\mathrm{p}<0.01$, respectively.

\subsection{The Effects of Rht9 on Seedling Root Characters and Coleoptile Length}

Coleoptile length (CL) was significantly reduced, by $19.80 \%$ (about $10.09 \mathrm{~mm}$ ), for the single dwarfing gene Rht 9 , in $\mathrm{F}_{7}$ lines of Xifeng 20, while it was even significantly increased by $14.22 \%$ in $\mathrm{F}_{6} \& \mathrm{BC}_{1} \mathrm{~F}_{5}$ Rht 9 dwarf lines of Jinmai47 which also carried Rht8 compared with taller parents (Table 5).
Rht9 dwarf lines of Jinmai 47 also showed 16.20\%, $18.18 \%$ and $33.33 \%$ significant decrease in the root surface area (RSA), average root diameter (ARD) and root volume (RV), respectively (Table 5). As to the Rht9 dwarf lines of Xifeng 20, no significant difference were observed on those root characters. These results indicated that the combination of Rht9 and Rht8 improved coleoptiles length.

Table 5. Root characters and coleoptile length of the $F_{7}$ Rht9 dwarfing lines of Xifeng20 and $F_{6} \& B_{1} C_{5}$ Rht9 dwarf lines of Jinmai47 with their corresponding tall parents.

\begin{tabular}{llllll}
\hline \multirow{2}{*}{ Traits } & \multicolumn{2}{l}{ Xifeng20/Granato } & \multicolumn{3}{l}{ Jinmai47/Granato } \\
\cline { 2 - 6 } & Dwarf & Xifeng20 & Difference & Dwarf & Xifeng20 \\
\hline RN & $3.33 \pm 0.25$ & $3.66 \pm 0.28$ & $-0.33(-9.00 \%) \mathrm{ns}$ & $4.00 \pm 0.58$ & $3.75 \pm 0.35$ \\
RL $(\mathrm{cm})$ & $34.25 \pm 2.73$ & $32.5 \pm 1.38$ & $1.75(5.40 \%) \mathrm{ns}$ & $27.14 \pm 1.87$ & $25 \pm 3.37$ \\
TRL $(\mathrm{cm})$ & $87.39 \pm 3.99$ & $82.62 \pm 6.41$ & $4.77(5.80 \%) \mathrm{ns}$ & $78.03 \pm 11.19$ & $77.99 \pm 9.75$ \\
RSA $\left(\mathrm{cm}^{2}\right)$ & $12.40 \pm 0.94$ & $11.78 \pm 1.05$ & $0.62(5.30 \%) \mathrm{ns}$ & $8.96 \pm 1.30$ & $0.25(6.70 \%) \mathrm{ns}$ \\
ARD $\left(\mathrm{mm}^{2}\right)$ & $0.20 \pm 0.03$ & $0.22 \pm 0.01$ & $-0.02(-9.09 \%) \mathrm{ns}$ & $0.18 \pm 0.01$ & $0.04(0.10 \%) \mathrm{ns}$ \\
RV $\left(\mathrm{cm}^{-3}\right)$ & $0.14 \pm 0.01$ & $0.13 \pm 0.02$ & $0.01(7.69 \%) \mathrm{ns}$ & $0.08 \pm 0.01$ & $0.22 \pm 0.01$ \\
CL $(\mathrm{mm})$ & $44.68 \pm 1.37$ & $55.67 \pm 2.51$ & $-10.99(-19.80)^{* *}$ & $57.11 \pm 7.78$ & $0.12 \pm 0.03$ \\
\hline
\end{tabular}

RN, Root number per plant; RL, Root length (cm); TRL, total root length $(\mathrm{cm})$; RSA, Root surface area $\left(\mathrm{cm}^{2}\right)$; ARD, Average root diameter (mm); RV, Root volume $\left(\mathrm{cm}^{-3}\right)$; CL, coleoptile length $(\mathrm{mm})$.

Data are means \pm SD (standard deviation) of each genotype. Difference was calculated as the value of dwarf lines minus that of the tall parent; the percentage difference was estimated as the difference to tall parent and is shown in parentheses. ns indicates that differences are not significant. * and ** indicates differences between the dwarfing lines and tall parent significant at $\mathrm{p}<0.05$, and $\mathrm{p}<0.01$, respectively.

\subsection{The Effects of Rht9 on Photosynthesis-Related Traits}

Rht 9 dwarf lines of Xifeng 20 showed $10.30 \%$ significant increase in flag leaf width (FLW), but $9.70 \%$ significant decrease in flag leaf length (FLL) than Xifeng 20. As to the Rht 9 dwarf lines of Jinmai47, no significant differences were observed on the flag leaf characters (Table 6). Relative leaf chlorophyll content (SPAD) was slightly increased by $2.20 \%$ and $2.90 \%$ in Rht9 dwarf lines of Xifeng20 and Jinmai47 dwarf lines, respectively (Table 6). Photosynthetic rate $(A)$, stomatal conductance $\left(\mathrm{g}_{\mathrm{s}}\right)$, and transpiration rate $(E)$ at grain filling stage were significantly reduced by $19.30 \%, 36.20 \%$ and $25.80 \%$, respectively in Rht 9 dwarf lines of Xifeng20, while photosynthetic rate $(A)$, and stomatal conductance $\left(\mathrm{g}_{\mathrm{s}}\right)$, and transpiration rate $(E)$ at grain filling stage were significantly increased by $26.40 \%, 45.80 \%$ and $19.50 \%$ 
respectively, and transpiration rate $(E)$ at anthesis stage was significantly reduced by $13.30 \%$ in $R h t 9$ dwarf lines of
Jinmai47, compared with Xifeng 20 and Jinmai 47, respectively (Table 6).

Table 6. Flag leaf characters, SPAD and gas exchange parameters of $F_{7}$ Rht 9 dwarfing lines of Xifeng20 and $F_{6} \& B C_{1} F_{5}$ Rht 9 dwarf lines of Jinmai47 with their corresponding tall parents.

\begin{tabular}{|c|c|c|c|c|c|c|}
\hline \multirow{2}{*}{ Traits } & \multicolumn{3}{|c|}{ Xifeng20/Granato } & \multicolumn{3}{|c|}{ Jinmai47/Granato } \\
\hline & Dwarf & Xifeng20 & Difference & Dwarf & Xifeng20 & Difference \\
\hline FLL (cm) & $15.33 \pm 1.13$ & $16.98 \pm 1.19$ & $-1.65(-9.70 \%)^{*}$ & $15.71 \pm 1.27$ & $15.52 \pm 1.46$ & $0.19(1.20 \%) \mathrm{ns}$ \\
\hline FLW (cm) & $1.61 \pm 0.06$ & $1.46 \pm 0.05$ & $0.15(10.30 \%)^{* *}$ & $1.55 \pm 0.19$ & $1.44 \pm 0.05$ & $0.11(7.60 \%) \mathrm{ns}$ \\
\hline$S P A D$ & $54.86 \pm 0.98$ & $53.68 \pm 1.16$ & $1.18(2.20 \%) \mathrm{ns}$ & $51.24 \pm 3.10$ & $49.8 \pm 1.67$ & $1.44(2.90 \%) \mathrm{ns}$ \\
\hline At anthesis & & & & At anthesis & & \\
\hline$A$ & $18.07 \pm 1.67$ & $19.62 \pm 0.52$ & $-1.55(-7.80 \%) \mathrm{ns}$ & $18.47 \pm 2.36$ & $16.67 \pm 1.92$ & $1.80(10.80 \%) \mathrm{ns}$ \\
\hline$g_{s}$ & $0.26 \pm 0.02$ & $0.26 \pm 0.02$ & $0.00(0.80 \%) \mathrm{ns}$ & $0.24 \pm 0.04$ & $0.27 \pm 0.02$ & $-0.03(-7.40 \%) \mathrm{ns}$ \\
\hline At grain filling & & & & At grain filling & & \\
\hline$A$ & $8.56 \pm 0.99$ & $10.62 \pm 0.34$ & $-2.06(-19.30 \%)^{* *}$ & $10.53 \pm 1.17$ & $8.33 \pm 3.27$ & $2.20(26.40 \%)^{*}$ \\
\hline$g_{s}$ & $0.29 \pm 0.03$ & $0.47 \pm 0.05$ & $-0.18(-36.20 \%)^{* *}$ & $0.35 \pm 0.05$ & $0.24 \pm 0.10$ & $0.11(45.80 \%)^{* *}$ \\
\hline$E$ & $5.59 \pm 0.55$ & $7.53 \pm 0.32$ & $-1.94(-25.80 \%)^{* *}$ & $7.23 \pm 1.12$ & $6.05 \pm 1.77$ & $1.18(19.50 \%)^{*}$ \\
\hline
\end{tabular}

FLL, flag leaf length (cm); FLW, Flag leaf width (cm); SPAD, relative leaf chlorophyll content; $A$, Photosynthetic rate $\left(\mu \mathrm{mol} \mathrm{m}^{-2} \mathrm{~s}^{-1}\right)$; gs, stomatal conductance $\left(\mathrm{mol} \mathrm{m} \mathrm{m}^{-2} \mathrm{~s}^{-1}\right) ; E$, transpiration rate $\left(\mathrm{mmol} \mathrm{m}^{-2} \mathrm{~s}^{-1}\right)$.

Data are mean $₫ \mathrm{SD}$ (standard deviation) of each genotype. Difference was calculated as the value of dwarf lines minus that of the tall parent; the percentage difference was estimated as the difference to tall parent and is shown in parentheses. ns indicates that differences are not significant. $*$ and $* *$ indicates differences between the dwarfing lines and tall parent significant at $\mathrm{p}<0.05$, and $\mathrm{p}<0.01$, respectively.

\subsection{Correlations Between Plant Height and Other Agronomic Traits}

Correlation analysis on plant height $(\mathrm{PH})$ and internode lengths showed that $\mathrm{PH}$ was positively and significantly correlated with the length of the third (I3L) and forth (I4L) internode with $\mathrm{r}=0.571,0.478$ in the $\mathrm{F}_{7}$ Rht 9 dwarf lines of Xifeng20; while plant height $(\mathrm{PH})$ was positively and significantly correlated with the length of the second (I2L), third (I3L), forth (I4L) and fifth (I5L) internode with $\mathrm{r}$ $=0.681,0.585,0.715,0.422$ in the $\mathrm{F}_{6} \& \mathrm{BC}_{1} \mathrm{~F}_{5}$ Rht9 dwarf lines of Jinmai47, respectively, but no signification correlation between $\mathrm{PH}$ and peduncle length (PL) (Table 7).

Table 7. Simple correlation coefficients ( $r$ ) between plant height and internode length and agronomic traits in the $F_{7}$ Rht 9 dwarfing lines of Xifeng20 and $F_{6} \& B C_{1} F_{5}$ Rht 9 dwarf lines of Jinmai47.

\begin{tabular}{lll}
\hline Traits & Xifeng20/Granato & Jinmai47/Granato \\
\hline I5L & $0.230 \mathrm{~ns}$ & $0.422^{* *}$ \\
I4L & $0.478^{*}$ & $0.715^{* *}$ \\
I3L & $0.571^{* *}$ & $0.585^{* *}$ \\
I2L & $0.268 \mathrm{~ns}$ & $0.681^{* *}$ \\
PL & $0.248 \mathrm{~ns}$ & $-0.068 \mathrm{~ns}$ \\
Spike length & $0.522^{*}$ & $-0.148 \mathrm{~ns}$ \\
Grain numbers spike $^{-1}$ & $-0.188 \mathrm{~ns}$ & $-0.215 \mathrm{~ns}$ \\
Fertile tillers plant $^{-1}$ & $-0.463^{*}$ & $-0.322^{*}$ \\
Biomass plant $^{-1}$ & $-0.128 \mathrm{~ns}$ & $0.227 \mathrm{~ns}$ \\
Grain yield plant $^{-1}$ & $-0.345 \mathrm{~ns}$ & $0.099 \mathrm{~ns}$ \\
Harvest index & $-0.373^{*}$ & $-0.381^{*}$ \\
\hline
\end{tabular}

PL, peduncle length $(\mathrm{cm})$; I2L, I3L, I4L, I5L, length of the second, third, fourth and fifth internode from top, respectively;

ns indicates correlations that are not significant, * indicates Significant at $\mathrm{p}<0.05, * *$ indicates Significant at $\mathrm{p}<0.01$

Correlation on plant height $(\mathrm{PH})$ with yield related traits indicated that in the $\mathrm{F}_{7} R h t 9$ dwarf lines of Xifeng 20, $\mathrm{PH}$ was negatively and significantly correlated with harvest index and the number of fertile tillers per plant ( $\mathrm{r}=0.373$, 0.463 ), and was positively and significantly correlated with spike length $(\mathrm{r}=0.522)$; while in the $\mathrm{F}_{6} \& \mathrm{BC}_{1} \mathrm{~F}_{5}$ Rht9 dwarf lines of Jinmai 47, $\mathrm{PH}$ was negatively and significantly correlated with harvest index and the number of fertile tillers per plant $(\mathrm{r}=0.381,0.322)$ (Table 7).

\section{Discussion}

Dwarfing in wheat breeding has been emphasized under situations of improved or more intensive husbandry methods, particularly increased use of fertilizers. Dwarfing genes $R h t B 1 b, R h t D 1 b$ and $R h t 8$ were widely used throughout the world to reduce the plant height, increase the lodging resistance, harvest index and yield potential. Dwarfing effects on plant height vary with genetic backgrounds and environments. For instance, GA-insensitive $R h t-B 1 b$ and $R h t$ $D 1 b$ alleles reduced around $20-25 \%$ of plant height to their wild-type allele [8-10]. The GAR dwarfing genes $R h t 4, R h t 8$, $R h t 9$, Rht12, and Rht13 reduced plant height by $12-50 \%$ while having small or negligible effects on coleoptile length $[17,30,31]$. Extreme dwarfism was associated with reductions in interception of photosynthetic active radiation, above ground biomass and harvest index and increased weed prevalence [32, 33]. To gain a more comprehensive understanding of dwarfing genes, Rht9 dwarf lines were developed from two populations resulting from crosses of tall Chinese winter wheat cultivars with Granaoto, the tetraploid donor of Rht9. In this study, Rht 9 dwarf lines of Xifeng20 reduced plant height by $25.38 \%$, averaged across two seasons and generations than taller parent, while $R h t 9$ dwarf lines of Jinmai47 reduced plant height by $9.39 \%$, averaged across two seasons and generations than taller parent, with final plant height at around $80 \mathrm{~cm}$, which were stronger than previous reported [18], as the experiments were conducted in field conditions without irrigation, but the rainfall in season affected greatly on plant height. The result of this study indicated that Rth9 alone could approximately have the 
similar height reducing effect with $R h t-B 1 b$, but much weaker effect when combined with $R h t 8$ allele in the double Rht9/Rht8 dwarfing lines. It should be noted that the reduction of plant height on average by $9.39 \%$ in the dwarf lines of Jinmai 47 was the effect of Rht 9 in a cultivar that also carries Rht8. Peduncle length was suggested as a useful indicator of yield capacity in dry environment [17], Various effects of Rth9 on different internodes may contribute to varied levels of height reduction by $R h t 9$. Investigation revealed that lengths of peduncle and all the internodes were significantly reduced in Rht 9 dwarf lines of Xifeng 20 to significantly reduce overall plant height, while, only the second and third internode length from the spike were significantly reduced in $R h t 9$ dwarf lines of Jinmai 47 . These results showed that $R h t 9$ had a moderately strong height reducing effect in common wheat which could be used to create germplasm with improved stature in wheat breeding. The effects by $R h t 9$ alone and by $R h t 9 / R h t 8$ on plant height reduction varied greatly with the genetic backgrounds, which suggested that selection of parents was important for its effective utilization.

The dwarf cultivars of wheat were mainly planted in irrigated environments or regions with abundant rainfall during the growing season. However, with the occurrence of severe water shortage and global warming, water resource for wheat planting become more and more limited. Thus the main challenges for the breeding of wheat cultivars for water limited areas is to increase the drought resistance, reduce plant height and increase the grain yields. The effect of different dwarfing genes on coleoptile length is an important indicator for breeding wheat with characteristics of drought resistance and water savings. Seedling vigor and coleoptile length have been important in successful crop establishment, especially in water limited areas. Short coleoptiles can reduce seedling emergence when sowing deep as shown by semidwarf wheats with GAI dwarfing genes Rht-Blb and Rht$D 1 b$ [11]. GAR dwarfing genes Rht4, Rht12, Rht13 and $R h t 18$ do not affect coleoptile length [11, 22, 32, 34]. In this study, coleoptile length was significantly reduced by $19.80 \%$ in the Rht 9 dwarf lines of Xifeng20 than Xifeng20, while it was significantly increased by $14.22 \%$ in the $R h t 9 / R h t 8$ double dwarf lines of Jinmai47 than Jinmai47. These results suggested that Rht8 may compensate the negative effect of $R h t 9$ on coleoptile length, offering opportunity to breed lines with double dwarfing genes Rht9/Rht8 for better coleoptile development. Root characters affect plant establishment, water and nutrient uptake in the field, especially in water limited regions. The effects of GAI Rht genes on wheat root system varied in previous studies, as little or only a slightly negative effect $[35,36]$ and strong negative effects observed in semi dwarf wheat cultivars with GAI dwarfing genes $R h t$ $B 1 b$ and $R h t-D 1 b$ [37, 38]. Most works on GAR dwarfing genes indicated that less negative effects were observed on wheat root system [22]. In this study, most root characters in the seedlings were slightly improved in Rht 9 dwarf lines of Xifeng 20; while root surface area, average root diameter and root volume were significantly reduced in $R h t 9 / R h t 8$ dwarf lines of Jinmai 47. The lack of negative effects from $R h t 9$ on root traits indicated that Rht 9 may have potential for improving root traits in wheat breeding for water limited regions.

Flag leaf assimilates are the most important contributor to the dry weight accumulation in grain [39]. Higher photosynthetic rate is associated with higher crop yield [40]. The flag leaf contributes greatly to the grain filling and grain yield as it has the highest potential for photosynthesis at the later growth stage of wheat. Though GAR dwarfing gene Rht13 was associated with narrower flag leaf width, it was improved in the RhtD1b and Rht13 double dwarfing lines [21]. In this study, Rht9 was associated with shorter and wider flag leaf in Xifeng20 background, while it was associated with longer and wider flag leaf in Jinmai47 background. Relative leaf chlorophyll content (SPAD) was also slightly higher in both Rht 9 dwarf lines of Xifeng20 and Jinmai47 while photosynthetic rate $(A)$, stomatal conductance $\left(\mathrm{g}_{\mathrm{s}}\right)$, and transpiration rate $(E)$ at grain filling stage were significantly reduced in Rht 9 dwarf lines of Xifeng20, but photosynthesis rate $(A)$, stomatal conductance $\left(\mathrm{g}_{\mathrm{s}}\right)$ were significantly increased in Rht $/$ Rht 8 double dwarf lines of Jinmai47. This result may suggest that the combination of $R h t 9$ with $R h t 8$ may improve photosynthetic capacity of flag leaf.

Primary determinants of grain yield are the number of fertile tillers per plant, grain number per spike, and grain weight. Fertile tillers per plant was increased by $R h t 5$ [41], but it was decreased by either Rht8 (11.2\%) or Rht13 $(5.5 \%)$ alone [42]. The presence of GAI dwarfing genes $R h t-B 1 b$ and $R h t-D 1 b$ is commonly associated with greater grain number per spike to increase grain number per unit area [43, 44], and GAR dwarfing genes Rht13, Rht12, Rht4 were also associated with increased grain number, while Rht8 had little effect on grain number [32]. Rht13 did not affect 1000-kernel weight whereas Rht8 significantly increased 1000-kernel weight [42]. In this study, the number of fertile tillers per plant was significantly increased, while 1000 kernels weight was slightly reduced in both $R h t 9$ dwarf lines of Xifeng20 and Jinmai47, and grain number per spike was significantly increased in $R h t 9$ dwarf lines of Xifeng20 but was decreased in $R h t 9 / R h t 8$ dwarf lines of Jinmai47. Rht 8 slightly decreased biomass and grain yield, finally the harvest index $(5.7 \%)$ [32]. In this study, biomass was slightly decreased in Rht9 dwarf lines of Xifeng20 but it was increased in $R h t 9 / R h t 8$ dwarf lines of Jinmai47; and grain yield per plant was increased in both Rht 9 dwarf lines of Xifeng20 and Jinmai47. Harvest index was significantly increased in $R h t 9$ dwarf lines of Xifeng20, while it was slightly increased in $R h t 9 / R h t 8$ dwarf lines of Jinmai47. These results may reflect effects of genetic backgrounds. This study indicated both single Rht 9 and its combination with $R h t 8$ increased the number of fertile tillers per plant, grain yield and harvest index.

\section{Conclusions}

As investigated in two populations derived from Xifeng 20 
and Jinmai47, Xifeng 20-Rht9 dwarf lines reduced plant height on average by $25.38 \%$, while on average by $9.39 \%$ in Jinmai47-Rht9/Rht8 dwarf lines. Height reduction of Rht 9 with the background of Xifeng 20 was greater than that of $R h t 9$ with the background of Jinmai47 that also carried Rht8. Coleoptile length was reduced in Rht 9 dwarf lines of Xifeng20 while coleoptile length was even increased in $R h t 9$ dwarf lines of Jinmai47 that also carries Rht8. Combination of Rht 9 with Rhts had slightly longer coleoptile than Jinmai47. Rht8 may partially compensate for the negative effect of Rht 9 on coleoptile length. Peduncle length and several internodes length were associated with reduction of plant height in both of two populations, which may have potential for freeing-up assimilates for partitioning to the growing ear. There were no adverse effects of Rht 9 on root characters and flag leaf characters, though slightly increased relative leaf chlorophyll content (SPAD) was observed.

$R h t 9$ was associated with increased number of fertile tillers on average by $11.25 \%$ in dwarf lines of Xifeng20 and $11.19 \%$ in dwarf lines of Jinmai47. Rht 9 was associated with increased grain yield and harvest index in both two populations while $R h t 9$ was associated with decreased spike length in both two populations. The influence of Rht 9 on spike number per spike, grain numbers per spike and harvest index was varied with different genetic backgrounds of Xifeng 20 and Jinmai 47. 1000- Kernel weight was slightly decreased by $4.43 \%$ and $4.61 \%$ in both $R h t 9$ dwarf lines of Xifeng 20 and Jinmai 47 while Rht 9 was associated with increased relative leaf chlorophyll content (SPAD) in both of two populations. This study indicated that the use of $R h t 9$ should be combined with proper parental lines selection for better coleoptile length, spike characters, especially improved spike length, grain numbers per spike and gas exchange parameters. As the works were carried out in single plant level grown in small plots of one location, further experiments for evaluating the effects of $R h t 9$ on grain yield should be tested in big plots under more conditions.

\section{Acknowledgements}

This study was supported by the National High Technology Research and Development Program of China (2013AA102902)", the Program of Introducing Talents of Discipline to Universities (B12007); Science and Technology Innovation Team Plan of Shaanxi Province (2014KCT-25); as well as ACIAR Project (CIM/2005/111) of Australia.

Abbreviations: $\mathrm{PH}$, plant height $(\mathrm{cm})$; SL, The spike length (cm); SNPS, Spikelet number per spike; FT, The number of fertile tillers per plant; GNPS, Grain number per spike; BM, The biomass per plant (gram); GY, Grain yield per plant (gram); HI, Harvest Index \%; TKW, 1000 kernel weight (gram); DSL, distance from base of the spike to the flag ligule (cm); PL, peduncle length $(\mathrm{cm})$; I2L, length of the second internode from top $(\mathrm{cm})$; I3L, length of the third internode from the top $(\mathrm{cm})$; I4L, length of the forth internode from top (cm); I5L, length of the fifth internode from top (cm); RN, Root numbers; RL, Root length (cm); TRL, total root length (cm); RSA, Root surface area $\left(\mathrm{cm}^{2}\right)$; ARD, Average root diameter (mm); RV, Root volume $\left(\mathrm{cm}^{-3}\right)$; CL, coleoptile length (cm); FLL, flag leaf length $(\mathrm{cm})$; FLW, Flag leaf width $(\mathrm{cm})$; SPAD, relative leaf chlorophyll content; $A$, Photosynthetic rate $\left(\mu \mathrm{mol} \mathrm{m} \mathrm{m}^{-2}\right)$; gs, stomatal conductance $\left(\mathrm{mol} \mathrm{m} \mathrm{m}^{-2} \mathrm{~s}^{-1}\right) ; E$, transpiration rate $\left(\mathrm{mmol} \mathrm{m} \mathrm{s}^{-2}\right)$.

\section{References}

[1] A. Goyal, R. Prasad, Some important fungal diseases and their impact on wheat production. in: A. Arya, A. Perello (Eds). Management of Fungal Plant Pathogens, CABI, ISBN 9781845936037, 2010, 362 .

[2] P. Hedden, The genes of the Green Revolution, Trends in Genetics. 19, 2003, 5-9.

[3] M. D. Gale, S. Youssefian, Dwarfing genes in wheat, in: GE Russed (Eds), Progress in Plant Breeding. Vol 1, Butterworths, London, 1985, 1-35.

[4] K. B. Borojevic, The transfer and history of 'reduced height genes' $(R h t)$ in wheat from Japan to Europe, Journal of Heredity. 96, 2005, 455-459.

[5] J. B. Reid, Gibberellin mutants. in: Blonstein AD, King PJ (EDs). Plant Gene Research, a Genetic Approach to Plant Biochemistry, New York, Springer-Verlag, 1986, 1-34.

[6] A. J. Worland, V. Korzum, M. S. Roder, M. W. Ganal, C. N. Law, Genetic analysis of the dwarfing gene (Rht8) in wheat. Part II, the distribution and adaptive significance of allelic variants at Rht8 locus of wheat as revealed by microsatellite screening, Theor Appl Genet. 96, 1998, 1110-1120.

[7] G. J. Rebetzke, R. Appels, A. Morrison, R. A. Richards, G. Mc Donald, M. H. Ellis, W. Spielmeyer, D. G. Bonnett, Quantitative trait loci on chromosome 4B for coleoptile length and early vigour in wheat (Triticum aestivum L.), Aust J Agric Res. 52, 2001, 1221-1234.

[8] J. Hoogendoorn, J. M. Rickson, M. D. Gale, Differences in leaf and stem anatomy related to plant height of tall and dwarf wheat, J Plant Phys. 136, 1990, 72-77.

[9] J. D. Butler, P. F. Byrne, V. Mohammadi, P. L. Chapman, S. D. Haley, Agronomic performance of Rht alleles in a spring wheat population across a range of moisture levels, Crop Sci. 45, 2005, 939-947.

[10] K. L. Mathews, S. C. Chapman, R. Trethowan, R. P. Singh, J. Crossa, W. Pfeiffer, M. van Ginkel, I. De Lacy, Global adaptation of spring bread and durum wheat lines nearisogenic for major reduced height genes, Crop Sci. 46, 2006, 603-613.

[11] G. J. Rebetzke, R. A. Richards, N. A. Fettell, M. Long, A. G. Condon, R. I. Forrester, T. L. Botwright, Genotypic increases in coleoptile length improves stand establishment, vigour and grain yield of deep-sown wheat, Field Crops Research. 100, 2007, 10-23.

[12] R. E. Allan, Agronomic comparisons between Rht1 and Rht2 semi dwarf genes in winter wheat, Crop Sci. 29, 1989, 1103-1108.

[13] G. J. Rebetzke, R. A. Richards, Gibberellic acid-sensitive dwarfing genes reduce plant height to increase kernel number and grain yield of wheat, Aust J Agric Res. 512, 2000, 235-245. 
[14] W. F. Schillinger, E. Donaldson, R. E. Allan, S. S. Jones, Winter wheat seedling emergence from deep sowing depths, Agron J. 90, 1998, 582-586.

[15] G. J. Rebetzke, R. A. Richards, V. M. Fischer, B. J. Mickelson, Breeding long coleoptile, reduced height wheat, Euphytica. 106, 1999, 159-168.

[16] G. J. Rebetzke, R. A. Richards, X. R. R. Sirault, A. D. Morrison, Genetic analysis of coleoptile length and diameter of wheat, Aust J Agric Res. 55, 2004, 733-743.

[17] M. H. Ellis, G. J. Rebetzke, A. G. Condon, W. Spielmeyer, R. A. Richards, The effect of different height reducing genes on early growth characteristics of wheat, Funct Plant Biol. 31, 2004, 583-589.

[18] M. H. Ellis, G. J. Rebetzke, F. Azanza, R. A. Richards, W. Spielmeyer, R. A. Richards, Molecular mapping of GR dwarfing genes in bread wheat, Theor Appl Genet. 111, 2005, 423-430.

[19] C. F. Konzak, Mutations and mutation breeding, In: Heyne, E. C. (Ed.), Wheat and Wheat Improvement, American Society of Agronomy, Madison, WI, 1987, 428-443.

[20] N. P. Loskutova, The influence of Rht 1-5, Rht 8-9 and Rht 13 genes on morphological characters and yield productivity of wheat. in: Slinkard, A. E. (Ed.), Proceedings of the 9th International Wheat Genetics Symposium, University Extension Press, University Saskatchewan, Saskatoon, 1998, 283-284.

[21] Y. Wang, C. Liang, D. Yingying, Zy. Yang, A. G. Condon, Y. $\mathrm{G}$. Hu, Genetic effect of dwarfing gene Rht13 compared with Rht-D1b on plant height and some agronomic traits in common wheat (Triticum aestivum L.), Field Crops Research. $162,2014,39-47$.

[22] Zy. Yang, J. Zheng, C. Liu, Y. Wang, A. G. Condon, Y. Chen, Y. G. Hu, Effects of the GA-responsive dwarfing gene Rht18 from tetraploid wheat on agronomic traits of common wheat, Field Crops Research. 183, 2015, 92-101.

[23] M. H. Ellis, W. Spielmeyer, K. R. Gale, G. J. Rebetzke, R. A. Richards, Perfect markers for the Rht-B1b and Rht-D1b dwarfing genes in wheat, Theor Appl Genet. 105 (2002) $1038-1042$.

[24] M. S. Clark, Plant Molecular Biology: A laboratory Manual, Springer-Verlag, Berlin Heidelberg, New York, 1997, 305-328.

[25] V. Korzun, M. S. Roder, M. W. Ganal, A. J. Worland, C. N. Law, Genetic analysis of the dwarfing gene $(R h t 8)$ in wheat, Part I. Molecular mapping of Rht8 on the short arm of chromosome 2D of bread wheat (Triticum aestivum L.), Theor Appl Genet, 96, 1998, 1104-1109.

[26] B. J. Bassam, G. Caetano-Anolles, P. M. Gresshoff, Fast and sensitive silver staining of DNA in polyacrylamide gels, Anal Biochem. 196, 1991, 80-83.

[27] J. C. Zadoks, T. T. F. C. Chang, A decimal code for the growth stages of cereals, Weed Res. 14, 1974, 415-421.

[28] G. Lobet, L. Pages, X. Draye, A novel image-analysis toolbox enabling quantitative analysis of root system architecture, Plant Physiol. 157, 2011, 29-39.

[29] H. Hu, Y. L. Bai, L. P. Yang, Y. L. Lu, L. Wang, H. Wang, Z. Y. Wang, Diagnosis of nitrogen nutrition in winter wheat (Triticum aestivum) via SPAD-502 and GreenSeeker, Chin. J.
Eco-Agric. 18, 2010, 748-752.

[30] T. L. Botwright, G. J. Rebetzke, A. G. Condon, R. A. Richards, The effect of rht genotype and temperature on coleoptile growth and dry matter partitioning in young wheat seedlings, Aust J Plant Physiol. 15, 2001, 417-423.

[31] G. J. Rebetzke, M. H. Ellis, D. G. Bonnett, B. Mickelson, A. G. Condon, R. A. Richards, Height reduction and agronomic performance for selected gibberellin-responsive dwarfing genes in bread wheat (Triticum aestivum L.), Field Crops Research. 126, 2012, 87-96.

[32] R. B. Austin, Yield of wheat in the United Kingdom: Recent advances and prospects, Crop Science. 39 (6), 1999, 1604-1610.

[33] J. E. Flintham, A. Börner, A. J. Worland, M. D. Gale, Optimizing wheat grain yield: Effects of Rht (gibberellininsensitive) dwarfing genes, Journal of Agricultural Science. 128 (1), 1997, 11-25.

[34] L. Chen, A. L. Phillips, A. G. Condon, M. A. J. Parry, Y. G. $\mathrm{Hu}$, GA-Responsive Dwarfing Gene Rht12 Affects the Developmental and Agronomic Traits in Common Bread Wheat, PLOS ONE. 8 (4), 2013, e62285.

[35] F. G. H. Lupton, R. H. Oliver, F. B. Ellis, B. T. Barnes, K. R. Howse, P. J. Welbank, P. J. Taylor, Root and shoot growth of semi-dwarf and taller winter wheats, Ann Appl Biol. 77, 1974, $129-144$.

[36] T. Wojciechowski, M. J. Gooding, L. Ramsay, P. J. Gregory, The effects of dwarfing genes on seedling root growth of wheat, J Exp Bot. 60, 2009, 2565-2573.

[37] K. H. M. Siddique, R. K. Belford, D. Tennant, Root: shoot ratios of old and modern, tall and semi dwarf wheats in a Mediterranean environment, Plant Soil. 121, 1990, 89-98.

[38] D. J. Miralles, G. A. Slafer, V. Lynch, Rooting patterns in near-isogenic lines of spring wheat for dwarfism, Plant Soil. 197, 1997, 79-86.

[39] R. B. Austin, J. A. Edrich, L. T. Evans, M. A. Ford, R. D. Blackwell, The fate of the dry weight, carbohydrates and $C_{14}$ lost from the leaves and stems of wheat during grain filling, Ann Bot. 41, 1977, 1309-1321.

[40] M. P. Reynolds, M. Balota, M. I. B. Delgado, I. Amani, R. A. Fischer, Physiological and morphological traits associated with spring wheat yield under hot, irrigated conditions, Aust $\mathbf{J}$ Plant Physiol. 21, 1994, 717-730.

[41] B. G. Daoura, L. Chen, Y. Du, Y. G. Hu, Genetic effects of dwarfing gene Rht-5 on agronomic traits in common wheat (Triticum aestivum L.) and QTL analysis on its linked traits, Field Crops Research, 2014, 22-29.

[42] Y. Wang, Y. Du, Zy. Yang, L. Cheng, A. G. Condon, Y. G. Hu, Comparing the effects of GA-responsive dwarfing genes Rht13 and Rht8 on plant height and some agronomic traits in common wheat, Field Crops Research. 179, 2015, 35-43.

[43] R. A. Fischer, Y. M. Stockman, Increased kernel number in Norin 10-derived dwarf wheat: evaluation of the cause, Aust $\mathbf{J}$ Plant Physiol. 13, 1986, 767-784.

[44] M. Nizam Uddin and D. R. Marshall, Effects of dwarfing genes on yield and yield components under irrigated and rainfed condi tions in wheat (Triticum aestivum L.), Euphytica. 42, 1989, 127-134. 